Annals of Plant Sciences

ISSN: 2287-688X

OPEN ACCESS

www.annalsofplantsciences.com

Research Article

\title{
Hepatoprotective efficacy of ethanolic extracts of rhizome Curcuma amada Roxb. In experimental rats
}

Ramnath Varadarajan ${ }^{*}$, Maria Caroline Rebellow Mathew ${ }^{2}$ and Seethalakshmi Souprayan ${ }^{3}$

${ }^{1}$ Biochemistry Department, School of Sciences, Jain University, Bengaluru, Karnataka, India.

2PG \& Research Department of Biochemistry, Dwaraka Doss Goverdhan Doss Vaishnav College (Autonomous),

Chennai, Tamilnadu, India.

3PG \& Research Department of Biochemistry, St. Joseph's College of Arts and Science, Cuddalore, Tamilnadu, India.

Received: 25-11-2017; Accepted: 15-12-2017

\begin{abstract}
The scope of this study is to evaluate the hepatoprotective efficacy of rhizome Curcuma amada Roxb. (CAR) in $\mathrm{CCl}_{4}$ induced hepatotoxicity in rats. Male Albino Wister rats were divided into six groups ( $\mathrm{n}=6$ ). Group I served as the normal control group and received olive oil (i.p. $0.5 \mathrm{~mL} / \mathrm{kg}$ b.w.) as a vehicle. Group II served as high dose group and received $400 \mathrm{mg} / \mathrm{kg}$ b.w $C A R$. Group III served as the carbon tetrachloride $\left(\mathrm{CCl}_{4}\right)$ group and received $\mathrm{CCl}_{4}$ (i.p., $0.1 \mathrm{~mL} / \mathrm{kg}$ b.w., $50 \% \mathrm{CCl}_{4}$ in olive oil). Groups IV-VI served as the treatment groups, and they received CARdissolved in distilled water orally at dose levels of 100,200 , and $400 \mathrm{mg} / \mathrm{kg}$ b.w., respectively, with $\mathrm{CCl}_{4}$ (i.p., 0.1 $\mathrm{mL} / \mathrm{kg}$ b.w., $50 \% \mathrm{CCl} 4$ in olive oil). All the groups were given the respective dosages twice a week for 28 days. The result of the marker enzymes AST, ALT, ALP and TBARS in the serum sample revealed an appreciable increase in groups IV, $\mathrm{V}$ and VI with respect to $\mathrm{CCl}_{4}$ treated group. This confirmed the hepatoprotective nature of $C A R$ there by deactivating the phase II detoxifying enzymes, preventing the formation of free radical and protecting the cell membrane from degeneration. The nonenzymatic antioxidants pattern of GSH, GPX and GST showed decreased levels with respect to group III. This confirmed that CAR has induced the GSH antioxidant system by increasing cellular defense against reactive free radicals and other oxidative species. The histological architecture of liver sections in Group-IV-VI showed more or less normal lobular pattern with mild degrees of fatty change, necrosis and lymphocyte infiltration almost comparable to those of control group. These results act as a supporting evidence to exhibit the hepatoprotective nature of $C A R$.
\end{abstract}

Keywords: Curcuma amada Roxb., Hepatoprotective, $\mathrm{CCl}_{4}$.

\section{Introduction}

The largest organ in our physiological system is the liver, which plays a major role in metabolism and has a number of functions in the body, including glycogen storage, decomposition of red blood cells, synthesis of proteins and hormones. The liver consists of water, proteins and their degradation products, carbohydrates and lipids, and their breakdown products, as well as coenzymes, vitamins, hormones, and organic substances [1]. The parenchymal cells are also involved in the synthesis of coagulation factors; removes unwanted wastes and toxic matter from the ECF[2]. Kupffer cells are involved in the blood-cell formation, production of antibodies and ingestion of foreign particles and cell debris [3-4]. The versatile role of liver makes it easily prone to infections and many diseases such as cancer, hepatitis, fatty liver, cirrhosis, alcohol damage and drug damage [5]. Diseases that interfere with the liver function will lead to derangement in its physiological functional ability. However, the regenerating nature makes it a more versatile organ.

\section{*Corresponding Author:}

Dr. V. Ramnath,

Biochemistry Department

School of Sciences, Jain University

Jayanagar, Bengaluru, Karnataka, India.

E-mail: drvramnath@gmail.com
Though liver plays a crucial role in transforming and clearing chemicals, it is more susceptible to toxic agents when their concentration is administered at higher amounts. Due to its exclusive metabolic function and close association with the gastrointestinal tract, the liver is prone to injury from drugs and other substances. Overdosage of medically advisable drugs results indamaging the organ and these are normally referred as hepatotoxins [6]. Drug-induced and hepatotoxicity liver damagethat accounts for anextensive number of failures emphasize the need for drug screening assays, such as stem cell-derived hepatocyte-like cells, that are capable of detecting toxicity early in the drug development process. Earlier reports reveal that more than $50 \%$ of acute renal failures are due to drug-induced liver [7-8].

Carbon tetrachloride $\left(\mathrm{CCl}_{4}\right)$ is widely used in fire extinguishers and as a precursor to refrigerants. $\mathrm{CCl}_{4}$ is generally used as an industrial solvent, and it is one of the best-characterized animal models of xenobiotic-induced free radical-mediated hepatotoxicity [9]. In animal experiments, $\mathrm{CCl} 4$ acts as a toxic agent by inducing reactive oxygen 
formation and depletes GSH phase II enzyme. It may reduce antioxidant enzymes and antioxidant substrates to induce oxidative stress. $\mathrm{CCl} 4$ induces liver injury caused by free radicals and lipid peroxidation, which can result in hepatic cell injury. Oxidative stress is an important factor in acute and chronic liver injury. Since the role of free radicals are inevitable in $\mathrm{CCl} 4$ induced hepatotoxicity, it seems be rational that compounds that counterbalance such radicals may have a hepatoprotective effect. Indeed, various natural products that protect against $\mathrm{CCl} 4$ induced hepatotoxicity have been reported [10].

Mango ginger is cultivated in many states of India, especially in Karnataka, Tamilnadu and West Bengal.The genus Curcuma (family Zingiberaceae) comprises of over 80 species of rhizomatous herbs. The genus has originated in the Indo-Malayan region and widely distributed in the tropics of Asia to Africa and Australia.The plant Curcuma Amada (mango ginger) belongs to ginger family Zingiberaceae and is very muchcorrelated to turmeric. An irony about the characteristic morphological appearance is its similarity to ginger, but resembles mango flavour. Mango flavor is mainly attributed to car-3-ene and cis-ocimene. The quality of mango-ginger is mainly determined by its volatile oil, non-volatile ether extract (NVEE), fibre and starch contents. More than 100 chemical constituents including curcuminoids, the bioactive compounds of Curcuma, have been reported in $C$. amadarhizomes, of which 121 have been identified.The percentage of amylose accounts to 43 which is almost the characteristics of both Curcumalongaand Zingiber officinale starch [11].The rhizome is composed of $86 \%$ moisture, $0.8 \%$ ash, $0.8 \%$ total sugars, traces of reducing sugars, $1.4 \%$ fibre, $0.1 \%$ essential oil and $6.9 \%$ starch on a fresh weight basis, and on a dry weight basis, $5.7 \%$ ash, $5.8 \%$ total sugar, traces of reducing sugars, $10.6 \%$ crude fibre, $0.9 \%$ essential oil and $45.6 \%$ starch. The rhizome finds extensive use in the indigenous systems of medicine. Recently, difurocumenonol and amadannulen compounds which are highly antioxidant and antimicrobial in nature have been isolated and characterized by Mango ginger. The aqueous and organic solvent extracts of mango ginger are antibacterial against Escherichia coli, Bacillus subtilis and Staphylococcus aureus. The different extracts like hexane, chloroform, ethyl acetate, acetone and methanol extracts are highly antibacterial against Bacillus cereus, B. subtilis, Micrococcus luteus, Staphylococcus aureus, Listeria monocytogenes, Enterococcus fecalis and Salmonella typhi. It also possesses antibacterial activity against free and bound phenolics mango ginger rhizomes. C. amada Roxb extract showed hypotriglyceridemic activity on Tritoninduced hyperlipidemic rats and also influences on both liver synthesis and blood clearance.Methanol extract of Curama amada rhizome exhibited mild hypoglycemic effect in mice and even at high dose of $650 \mathrm{mg} / \mathrm{kg}$ b.w. no noticeable toxic effects were associated with the plant extract [12]. Earlier studies reported that the efficacy of methanolic extracts of both rhizome and leaves of curcuma amada has a high ability to scavenge $\mathrm{H}_{2} \mathrm{O}_{2}$. Methanolic extracts of both leaves and rhizomes efficiently inhibited the superoxide and nitric oxide production in vitro followed by aqueous and chloroform extracts. It is reportedly used in antiallergic formulations of herbal plants. Ethyl alcohol extract of mango ginger comprises of chemical compounds with hydroxyl, ester, carbonyl and olefin functional groups. They were found to be responsible for anti-inflammatory activity of the extract in acute and chronic administration in albino rats [13]. Since the rhizome has proved to have multi medicinal activity, the active compounds extracted with ethanol have been tried in this study to analyze its hepatoprotective efficacy.

\section{Material and Methods}

\section{Plant material}

Fresh and healthy mango ginger (Curcuma Amada Roxb.) rhizomes were procured from the local market, Cuddalore, Tamilnadu, India. The rhizomes were washed, sliced, dried and powdered.

\section{Extraction of plant material:}

The plant material was shade dried under room temperature and reduced to fairly coarse powder and finally extracted successively with $95 \%$ ethanol using soxhlet apparatus. The extract was dissolved in water to the final desired concentration.

\section{Animals:}

Adult male Wister rats with body weight of 200$220 \mathrm{~g}$ were used in this study. The animals were maintained in an air-conditioned animal house at a temperature of $22 \pm 2 \circ \mathrm{C}$, relative humidity of $57 \pm 2 \%$ and photo-cycle of 12:12 h light and dark. The animals experimental were performed according to the institute's ethical committee approval and guidelines

\section{Chemicals:}

The drugs including carbon tetrachloride, assay kits for analyzing enzymatic and non-enzymatic parameters were purchased from Merck chemicals. Allother chemicals used in this work were of analytical grade.

\section{Experimental protocol}

Eighteen rats were grouped into six $(n=6)$ :

Group I served as the normal control group and received olive oil (i.p. $0.5 \mathrm{~mL} / \mathrm{kg}$ b.w.) as vehicle twice a week intraperitoneally for 28 days.

Group II served as Curcurma amada Roxb.A control group andreceived Curcurma amadaRoxb dissolved in distilled water orally (gavage) at a dose level of $400 \mathrm{mg} / \mathrm{kg}$ b.w. for 28 days.

Group III served as the carbon tetrachloride group and received CCl4 (i.p., $0.1 \mathrm{~mL} / \mathrm{kg}$ b.w., $50 \% \mathrm{CCl}_{4}$ 
in olive oil) twice a week intraperitoneally for 28 days.

Groups IV-VI served as the treatment groups, and they received Curcurma amada Roxb. Dissolved in distilled water orally (gavage) at dose levels of 100 , 200, and $400 \mathrm{mg} / \mathrm{kg}$ b.w., respectively, with CCl4 (i.p., $0.1 \mathrm{~mL} / \mathrm{kg}$ b.w., $50 \% \mathrm{CCl} 4$ in olive oil) twice a week for 28 days.

Hepatotoxicity was induced inCCl4, CCl4+CAR(low), $\mathrm{CCl} 4+$ (medium), $\mathrm{CCl} 4+$ (high) groups by an injection of $\mathrm{CCl} 4(0.1 \mathrm{ml} / \mathrm{kg}$ body weight, 1:1 with Olive oil i.p). The ethanol extract of $C A R$ was administered orally for 28 days through gavage.

\section{Biochemical evaluation}

At the end of the $28^{\text {th }} \mathrm{day}$, the rats were maintained in fasting condition for $12 \mathrm{~h}$ and sacrificed under mild anesthesia. Blood and liver were immediately obtained after the animals were sacrificed. Liver tissue samples were taken from the left liver lobe and cut into two pieces. One piece was fixed in formalin $(10 \%)$ for pathological examination. The other piece was utilized for biological analysis. Liver homogenates $(10 \%, \mathrm{w} / \mathrm{v})$ were obtained in $50 \mathrm{mM}$ phosphate buffer $(\mathrm{pH} 7.0)$ and stored at $-80^{\circ} \mathrm{C}$ for analysis within two weeks. The blood was allowed to clot for $30 \mathrm{~min}$; the serum was separated by centrifuging at $37^{\circ} \mathrm{C}$ and was used for biochemical estimations. The activities of enzymatic and nonenzymatic parameters such as ALT, AST, ALP, SOD, CAT, GSH, GPX, GST, TBARS and Totalproteinwere determined.

\section{Serum preparation}

The blood collected in a heparinised centrifuge tubewas centrifuged at $2000 \mathrm{rpm}$ for $10 \mathrm{~min}$ and the serum was separated.

\section{Tissue homogenate preparation}

Liver tissues $(250 \mathrm{mg}$ ) were sliced into pieces and homogenised in appropriate buffer in cold condition ( $\mathrm{pH} 7.0$ ) to give $20 \%$ homogenate (w/v). The homogenate were centrifuged at $1000 \mathrm{rpm}$ for $10 \mathrm{~min}$ in cold centrifuge. The supernatant was separated and used for various biochemical estimations.

\section{Tissue sampling for histopathological study}

A part of the excised liver graftfrom each group was perfused with cold physiological saline, followed by formalin $(10 \%)$. It was then dehydrated on treatment with a series of different concentration of ethanol and embedded in paraffin wax. 3-5 $\mu \mathrm{m}$ thick sections were cut using a microtome and stained with haematoxylin and eosin. Using light microscope, the specimens were evaluated. All histopathological changes were examined by an experienced pathologist.

\section{Result and Discussion}

\section{Biochemical analysis}

\section{Serum Levels of AST, ALT and ALP}

ALTand AST are transaminases mainly synthesized in the liver. ALT is responsible for catalyzing thereversible transfer of an amino group from Lalanine to $\alpha$-ketoglutarate, liberating the products pyruvate and L-glutamate. Similarly, AST catalyzes the interconversion of aspartate and $\alpha$-ketoglutarate to oxaloacetate and glutamate. Both these transaminases utilize the coenzyme pyridoxal phosphate (PLP). Alkaline phosphatase (ALP) is a hydrolaseenzyme involved in the process of removing the phosphate group from many macromolecules.

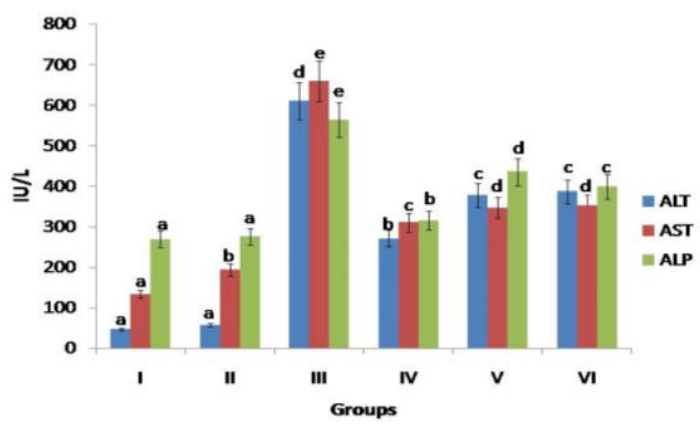

Figure 1. Serum Levels of AST, ALT and ALP: Alanine aminotransferase (ALT), Aspartate aminotransferase (AST), Alkaline phosphatase (ALP), Group I - control (vehicle -olive oil) Group II - higher dose (CAR) extract, Group -III CCl4, Group IV- lower dose (100mg/kg b.w), Group VMedium dose(200mg/kgb.w), Group VI- higher dose $(400 \mathrm{mg} / \mathrm{kg}$ b.w). The data are presented as \pm S.D of three individual experiments. Means bearing different superscripts, differed significantly by Duncan's multiple arrange analysis at $\mathrm{P}>0.05$.

The results of serum AST, ALP and ALT revealed a significant decrease in the level of enzymes in the group IV, V and VI with respect to group III. The levelof these enzymes in the group II (higher dose) do not reveal much variation with respect to group I indicating that higher doses of $C A R$ does not influence much on the toxicity towards liver function. The levels of serum ALT and AST in the group V and VI showed significant variation with respect to group IV revealing that, increased concentration of CAR has induced the hepatoprotective process. The results also showed, there is no significant increase in the levels of ALP and AST between the group V and VI confirming that increasing concentration $400 \mathrm{mg} / \mathrm{kg}$ has not influenced much on the hepatoprotective activity, but the levels of ALP has shown significant difference between the groups IV, V and VI. These results validate that $C A R$ acts as hepatoprotective agent there by deactivating the phase II detoxifying enzymes, preventing the formation of free radical and protecting the cell membrane from degeneration. 


\section{Levels of SOD and CAT}

In the physiological system, the oxidation of cellular components by reactive oxygen species (ROS) is usually overcome by Superoxide dismutase enzymes (SODs). ROS are formed in many conditions such as injury, plant metabolic activity, nutrient deficiencies, photo inhibition, exposure to toxic metals, herbicides and UV or gamma rays. The production of $\mathrm{O}_{2}$ and $\mathrm{H}_{2} \mathrm{O}_{2}$ from superoxide $\left(\mathrm{O}_{2}{ }^{-}\right)$ is catalyzed by SODs thereby converting them to less harmful reactants. Further, the hydrogen peroxide is decomposed to water and oxygen by the enzyme Catalase (CAT) thus protecting the cell from oxidative damage by reactive oxygen species (ROS). Apart from the decomposing nature of $\mathrm{H}_{2} \mathrm{O}_{2}$ by catalase, it is also involved in neutralizingmany toxins and metabolites such as phenols, acetaldehyde, formic acid and alcohols.

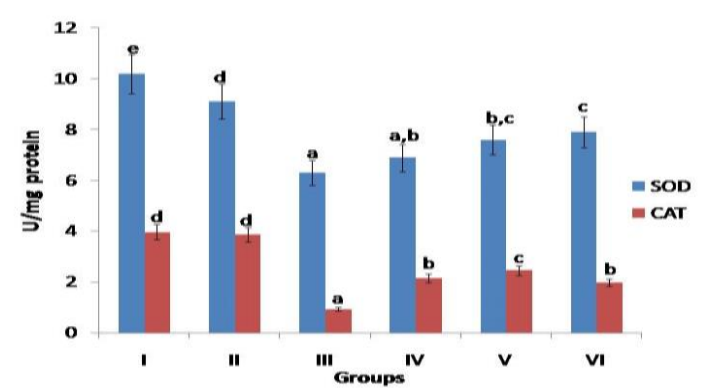

Figure 2. Levels of SOD, CAT:

SOD- Superoxide dismutase, CAT- Catalase, Group I - control (vehicle -olive oil) Group II - higher dose (CAR) extract, Group -III CCl4, Group IVlower dose $(100 \mathrm{mg} / \mathrm{kg}$ b.w), Group V- Medium dose(200mg/kgb.w), Group VI- higher dose $(400 \mathrm{mg} / \mathrm{kg}$ b.w) The data are presented as \pm S.D of three individual experiments. Means bearing different superscripts, differed significantly by Duncan's multiple arrange analysis at $\mathrm{P}>0.05$.

SOD and CAT levels in this study show decreased values in the groups IV, V and VI treated with $C A R$ extract. A significant increase in the levels of catalase and SOD were observed in group $\mathrm{V}$ with respect to groups IV andVI. This increase in the levels of CAT and SOD in CAR treated groups IV, $\mathrm{V}$ and VI with respect to group III, confirms the free radical scavenging capability of $C A R$ there by reducing lipid peroxidation.

\section{Levels of TBARS}

One of the important byproduct formed during lipid peroxidation is the TBARS (Thiobarbituric acid reactive substances), and its assay plays a vital role in assessing the hepatoprotective activity.

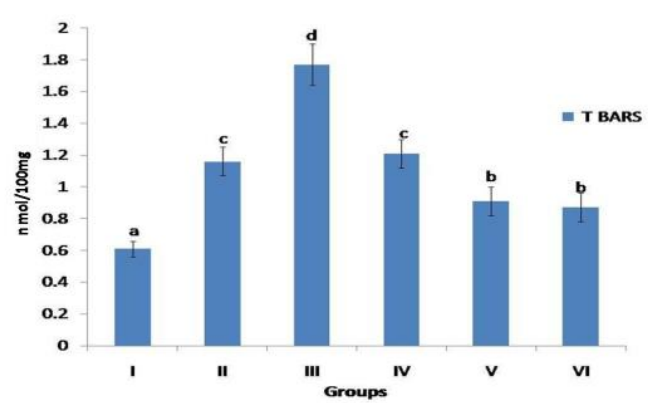

Figure 3. Levels of TBARS:

T BARS Thiobarbituricacid Group I - control (vehicle -olive oil) Group II - higher dose (CAR) extract, Group -III CCl4, Group IV- lower dose $(100 \mathrm{mg} / \mathrm{kg}$ b.w), Group V- Medium dose (200mg/kgb.w), Group VI- higher dose (400mg/kg b.w). The data are presented as \pm S.D of three individual experiments. Means bearing different superscripts, differed significantly by Duncan's multiple arrange analysis at $\mathrm{P}>0.05$.

The results of TBARS indicates significant increase in the groups IV, V and VI with respect to groups I and III. These results act as a supporting evidence to confirm the anti lipidperoxidation effect of $C A R$. Increased dosage in group V and VI does not show any significant change but a significant change was observed group IV and III. These results indicate the potential nature of $C A R$ extract in reducing the free radical generation through free radical scavenging mechanism.

\section{Levels of GSH, GPX and GST}

Glutathione exists in both reduced (GSH) and oxidized (GSSG) states. The unstable reactive oxygen species generated during the metabolic process receivesa reducing equivalent to become stable. Glutathione itself becomes reactiveon donating an electron, but immediately reacts with another reactive glutathione to form glutathione disulfide (GSSG). Such a reaction is possible due to the fairly high concentration of glutathione in cells. Removing conjugates of GSH from the cell depends upon the activity of GST which is again under the control of steady supply of GSH from the synthetic enzymes as well as the action of specific transporters. The important function of GST is to induce the GSH and thereby protecting nucleic acids and cellular proteins from non-polar xenobiotic substrates. The main biological role of Glutathione peroxidase (GPX) is to protect the organism from oxidative damage. GPX is involved in the reduction of lipid hydroperoxides to their respective alcohols. The hydrogen peroxide formed is effectively reduced to water. 

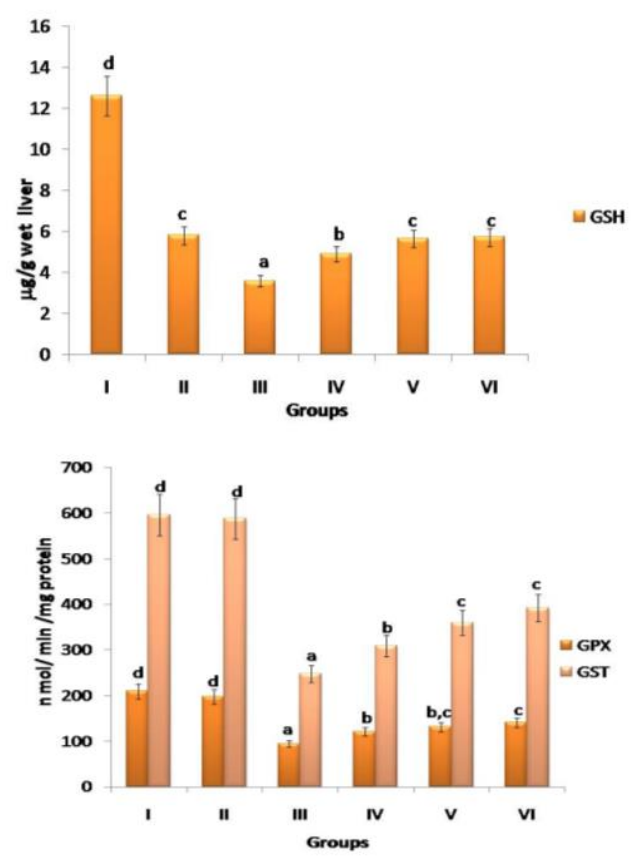

Figure 4a. Levels of GSHFigure 4b Levels of GSH, GPX, GST

Glutathione peroxidase, Glutathione (GSH), Glutathione $S$-transferase (GST), Group I - control (vehicle -olive oil) Group II - higher dose (CAR) extract, Group -III CCl4, Group IV- lower dose $(100 \mathrm{mg} / \mathrm{kg}$ b.w), Group V- Medium dose (200mg/kgb.w), Group VI- higher dose $(400 \mathrm{mg} / \mathrm{kg}$ b.w). The data are presented as \pm S.D of three individual experiments. Means bearing different superscripts, differed significantly by Duncan's multiple arrange analysis at $\mathrm{P}>0.05$. The enzymes $\mathrm{GP}_{\mathrm{x}}, \mathrm{GST}$ and GSH showed asignificant increase in their levels with respect to group III ( $\mathrm{CCl}_{4}$ treated). The results also confirmed that increased concentration (group II $400 \mathrm{mg} / \mathrm{kg}$ b.w) does not reveal any marked changes in the levelof these enzymes with respect to group I (control). These results do supplement for confirmation of efficacy of $C A R$ acting against antioxidant system by escalating cellular defense against ROS.

\section{Levels ofTotal Protein}

Proteins play a diverse function in the maintenance of the physiological status. The outcome of this study revealed a decreased level of total proteins in group III (CCl4 treated) with respect to all the other groups. This result confirms the detrimental nature of $\mathrm{CCL}_{4}$ towards hepatotoxicity. Furthermore, a significant increase in protein levels in groups IV, V andVI revealed that $C A R$ had stimulated protein synthesis through regeneration process and the formation of new hepatocytes.

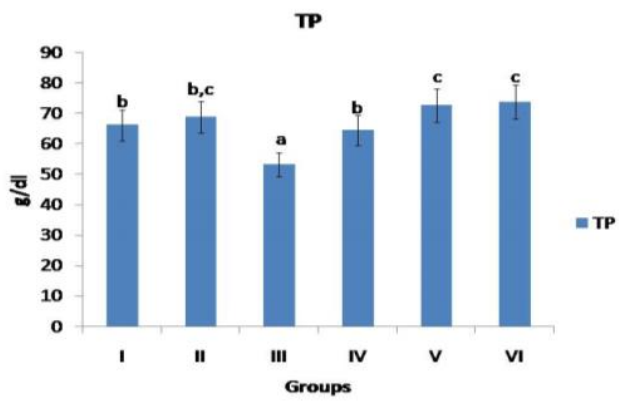

Figure 5. Levels of Total Protein: TP - Total protein, Group I - control (vehicle -olive oil) Group II - higher dose (CAR) extract, Group -III CCl4, Group IV- lower dose (100mg/kg b.w), Group V- Medium dose(200mg/kgb.w), Group VIhigher dose (400mg/kg b.w) The data are presented as \pm S.D of three individual experiments. Means bearing different superscripts, differed significantly by Duncan's multiple arrange analysis at $\mathrm{P}>0.05$.

\section{Histopathological evaluation}

Histopathology evaluation of control rats treated with Curcuma Amada Roxb. (Groups I and II high dose) showed normal hepatic cells with wellpreserved cytoplasm with prominent nucleus and nucleolus and a clearly visible central vein (Fig. 6A, $\mathrm{B})$. The liver sections of the CCl4-intoxicated rats showed immense fatty changes, necrosis, cell swelling, and lymphocyte infiltration, absence of cellular boundaries and the central vein is surrounded by kupffer cells (Fig. 6C). The symptom in $\mathrm{CCl}$-induced group was more severe than the other groups. The histological architecture of the liver sections of rats treated with 100,200 and $400 \mathrm{mg} / \mathrm{kg}$ CAR showed a more or less normal lobular pattern with mild degrees of fatty change, necrosis and lymphocyte infiltration almost comparable to those of control group (Fig. 6D, E, F). Even though, a normal histological architecture was observed in the liver sections in groups IV, V and VI, there was a significant change in the histopathological pattern at increasing doses of CARin groups $\mathrm{V}$ and $\mathrm{VI}$, hence significantly reducing the liver damage scores. There was no significant alteration in control rats treated with higher dose of $C A R$, the histological observations act as supportive evidence in relation to the results obtained from the serum enzyme assays. Histopathological sections also revealed not much comparable differences between groups V and VI. Hence, a concentration of $200 \mathrm{mg} / \mathrm{kg}$ b.w of $C A R$ administration revealed considerable hepatoprotective activity which was obvious through histopathological observations. 

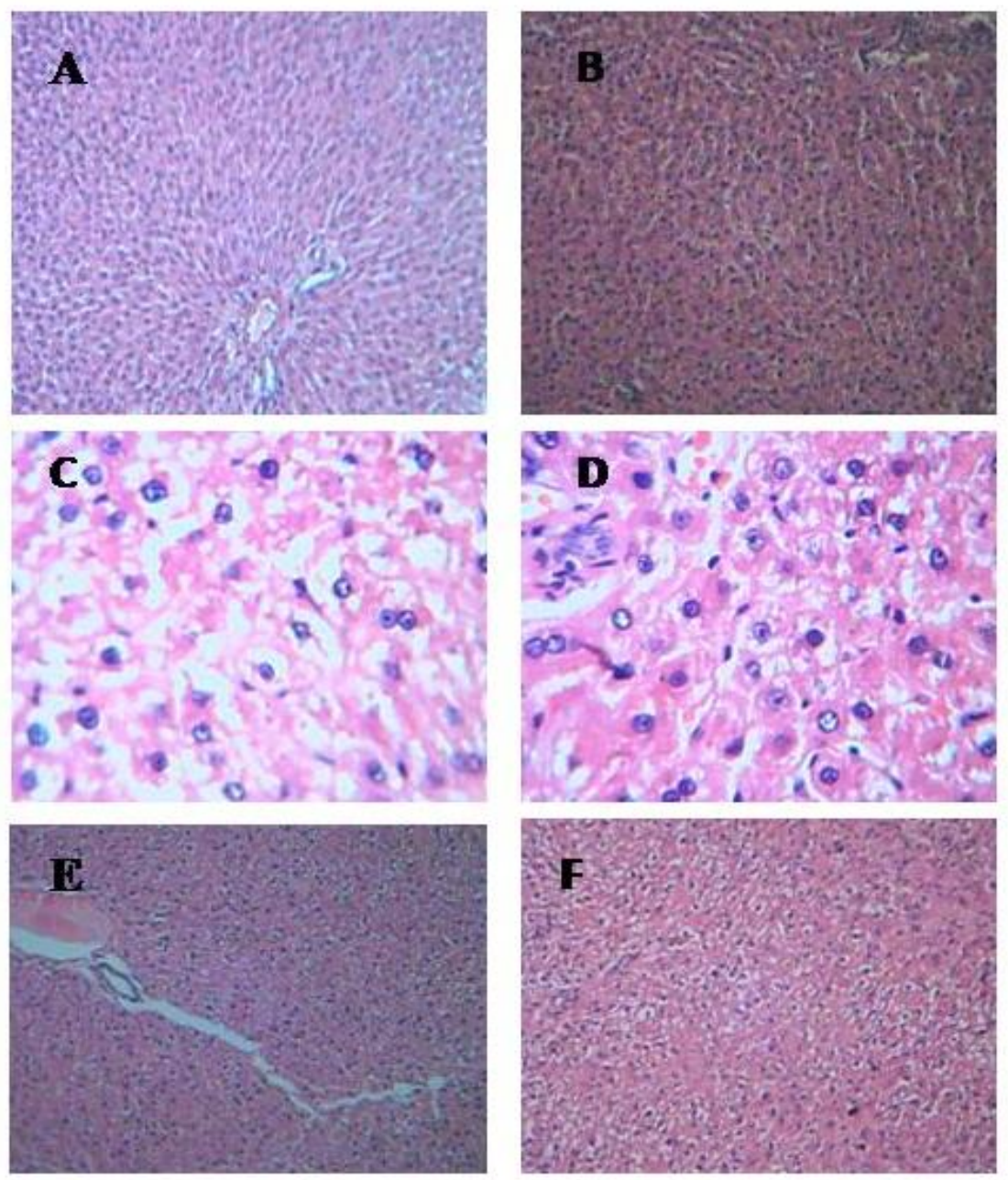

Figure 6A: Liver section of normal control showing normal central vein and radiating hepatocytes Figure 6B: Liver section from CARextract treated animals shows normal centralvein (C.V.) and hepatocyte Figure 6C: Liver section of CCl4-treated ratsrevealing fatty degeneration, hepatocyte necrosis, inflammatory cells infiltration and normalhepatocyte ( $\left.\mathrm{H} \& \mathrm{E}^{*} 640\right)$ Figure 6D: Liver section from rat treated with $100 \mathrm{mg} / \mathrm{kg}$ b.w. + CCl4 shows fatty degenerationnecrosis and infiltration of inflammatorycells Figure 6E: Liver section from rat treated with $200 \mathrm{mg} / \mathrm{kg}$ b.w. + CCl4 shows infiltration of inflammatory cells with normal hepatocyte Figure 6F: Liver section from rat treated with400mg/kg b.w. + CCl4 shows fatty degeneration, infiltration of inflammatory cells

\section{Conclusion}

Earlier reports act as an evidence to confirm the versatile medicinal properties of Curcuma amada Roxb and its extensive application in the native system of medicine. The present study also proved the medicinal efficacy of ethanolic extract of $C A R$ in experimental rats for its hepatoprotective nature. The result of the marker enzymes in the serum sample, levels of TBARS and non-enzymatic antioxidants pattern strongly authenticate the hepatoprotective behavior and free radical scavenging efficacy of the rhizome. The histological studies also substantiate the hepatoprotective behavior of the rhizome Curcuma amada Roxb.

\section{References}

1. X Shen, Tang Y, Yang R, Yu L, Fang T, and Duan JA. "The protective effect of Zizyphus jujube fruit on carbon tetrachloride induced hepatic injury in mice by anti-oxidative activities”. J Ethnopharmacol 122.3 (2009): 555-560.

2. JA Patel, and Shah US. "Hepatoprotective activity of Piper longum traditional milk extract on carbon tetrachloride induced liver toxicity in Wistar rats". Bol Latinoam Caribe Plant Med Aromat 8.2 (2009): 121-129.

3. B Halliwell, and Gutteridge JMC.'Free radicals in biology and medicine". Nueva York: Oxford University Press (2007). 
4. A Amin, Mahmoud-Ghoneim D, and Zizyphusspina-christi. "Protects against carbon tetrachloride induced liver fibrosis in rats". Food Chem Toxicol 47.8 (2009): 2111-2119.

5. J Ananthi, Prakasam A, and Pugalendi KV. "Antihyperglycemic activity of Eclipta alba leaf on alloxan induced diabetic rats". Yale J Biol Med 76.3 (2003): 97-102.

6. F Stickel, and Schuppan D. "Herbal medicine in the treatment of liver diseases". Dig Liver Dis 39 (2007): 293-304.

7. KR Kirtikar, and Basu, BD.'Indian medicinal plants". Dehradun: Bishen Singh \& Mahendra Paul Singh (2005): 2078-2079.

8. A Chatterjee." The treatise of indian medicinal plants". New Delhi, India: CSIR Publication (1997): 69-70.

9. M Bathori, Toth I, Szendrei K, and Reisch J. "Ecdysteroids in Spinacea oleracea and Chenopodium bonus-Henericus". Phytochemistry 21 (1982): 236-238.

10. KH Janbaz, and Gilani AH. "An assessment of the potential of protopine to inhibit microsomal drug metabolizing enzymes and prevent chemical induced hepatotoxicity in rodents". Pharmacological Research 38 (1998): 215-218.

11. CD Klaassen. "The pharmacological basis of therapeutics". 7th Edition, New York, Toronto, London, Macmillan (1985):1635-1636. Klaui. "Industrial and commericial uses of carotenoids". Carotenoid Chemistry and Biochemistry Briton G and Godwin TW (1982): 309-317.

12. Y Oshima, Kawakami Y, Kiso Y, Hikino H, Yang L, and Yen KY. "Antiihepatotoxic principles of Aeginatia indica herbs". Syhoyakugaku Zasshi 30 (1984): $198-200$.

13. SC Lin, YH Chen, CY Hsu, and SH." The Hepatoprotective and therapeutic effect of propolis ethanol extract on chronic alcoholinduced liver damage". Am. J. Chin. Med 25 (1997): 325 - 332.

\section{Cite this article as:}

Ramnath Varadarajan., Maria Caroline Rebellow Mathew. and Seethalakshmi Souprayan. Hepatoprotective efficacy of ethanolic extracts of rhizome Curcuma amada Roxb. in experimental rats. Annals of Plant Sciences 7.1 (2018) pp. 1966-1972.

do http://dx.doi.org/10.21746/aps.2018.7.1.9 